\title{
Evaluation of Power Distribution based on Power Losses on Transmission Interconnection
}

\author{
Mega Agustina ${ }^{1,2}$, A.N. Afandi ${ }^{1,2}$
}

Authors

${ }^{1}$ Department of Electrical Engineering Universitas Negeri Malang, Indonesia, megagustina23897@gmail.com

${ }^{2}$ Semart Power and Advanced Energy Systems Research Center, Batu, Indonesia, an.afandi@ieee.org

Corresponding: an.afandi@ieee.org

\begin{abstract}
This paper discusses the analysis of continuity of power delivery and network losses in the scenario of adding $150 \mathrm{kV}$ to the Malang Raya transmission network. The discussion in this paper is based on the increasing load growth conditions in Malang Raya and the condition of the Malang $150 \mathrm{kV}$ main system which is centralized in the Kebonagung Substation so that a scenario of adding $150 \mathrm{kV}$ transmission network interconnection is needed to increase the capacity, reliability, and improvement of the Malang Raya system. Based on the simulation results before the scenario of adding 150 $\mathrm{kV}$ transmission network losses in the poor $150 \mathrm{kV}$ main system by $0.02 \mathrm{MW}$, whereas after the scenario of adding $150 \mathrm{kV}$ transmission network the overall losses in the $150 \mathrm{kV}$ main unfortunate main system were $0.009 \mathrm{MW}$
\end{abstract}

Keywords

Interconnection transmission network, Network addition scenario, Continuity of power distribution, Network losses.

\section{Introduction}

To date, the development in Greater Malang is at a high time, particularly in tourism, industries, and education; hence, new loads appeared. Besides, the huge project in the north and south area also supports the load growth [1]-[6]. The $150 \mathrm{kV}$ primary system in Greater Malang is a central network system with the power distribution center located in Kebonagung Main Substation. The transmission network interconnected connects the JAMALI system power grid that is distributed through Lawang-Kebonagung Main Substations, PLTA Sutami-Wlingi that is distributed through the Sutami-Kebonagung Main Substations, Kebonagung-Sengkaling Main Substations, and Kebonagung-Pakis Main Substations. The primary system in Greater Malang serves three cities' load: Malang city overloads the Kebonagung Main Substation, Malang Regency overloads the Pakis Main Substation, and Batu City overloads the Sengkaling Main Substation.

Added with the central system topology, Sengkaling Main Substation and Pakis Main Substation depend on the condition of Kebonagung Main Substation. This situation influences the electricity condition of Greater Malang in the future. The increasing load could create overcapacity in Kebonagung Main Substation. In turns, the overcapacity creates further damage and disruption in Kebonagung Main Substation and disturbs the power distribution in Sengkaling and Pakis Main Substations. There needs an additional $150 \mathrm{kV}$ transmission network interconnection that connects the Lawang-Pakis Main Substations, Lawang-Sengkaling Main Substations, Sutami-Sengkaling Main Substations, and SutamiPakis Main Substations to improve the capacity, reliability, and refinement of the system. Other than that, the scenario could produce an alternative power distribution scenario and losses analysis before and after the additional $150 \mathrm{kV}$ transmission network.

\section{Interconnection Network}

Network interconnection connects several substations through an electrical network that serves the load in the electricity system [4], [7]-[9]. The interconnected network system that is used in Indonesia is $70 \mathrm{kV}, 150 \mathrm{kV}$, and $500 \mathrm{kV}$. The advantages of the interconnected system are below:

- continuous reliability of electricity service,

- generator center does not need to work optimally to serve the load in a system with the interconnected network,

- power plants supplying electricity to one another through a central load regulator. 
The $150 \mathrm{kV}$ transmission network interconnection system is used in a transmission network with medium to the medium range at a considerable amount of power or energy. Network losses is a gap between the distributed energy with the used energy. Network losses can be categorized based on technical and non-technical losses [10]-[12]. Technical loss is caused by the network material or devices, while non-technical loss is caused by faulty installation and damage to material or network equipment. The material type and the length influence the magnitude of the transmission line reactant, and in turn, affect the transmission loss. Besides, the amount of current that stream in a transmission line also influences the loss because a loss is the result of multiplication between squared current with line reactant [13]-[15]. Therefore, higher current in a transmission line creates a more considerable loss. The new transmission line increases the power distribution continuity, reduces loss in the transmission network, and improve the reliability of the power plant system.

The $150 \mathrm{kV}$ primary system in Greater Malang is a central network system with the power distribution center located in Kebonagung Main Substation. The transmission network interconnected connects the JAMALI system power grid that is distributed through Lawang-Kebonagung Main Substations, PLTA Sutami-Wlingi that is distributed through the Sutami-Kebonagung Main Substations, Kebonagung-Sengkaling Main Substations, and Kebonagung-Pakis Main Substations. The primary system in Greater Malang serves three cities' load: Malang city overloads the Kebonagung Main Substation, Malang Regency overloads the Pakis Main Substation, and Batu City overloads the Sengkaling Main Substation.

\section{Method}

This research aimed to predict the continuity and loses in the scenario of another $150 \mathrm{kV}$ transmission network in Greater Malang. A literature study was used as the base of analysis. The initial design condition simulation is shown in the following figures. Scenario 1 was another transmission network in Lawang-Sengkaling Main Substations, Scenario 2 was a new transmission network in Lawang-Pakis Main Substations, Scenario 3 was a new transmission network in Sutami-Sengkaling Main

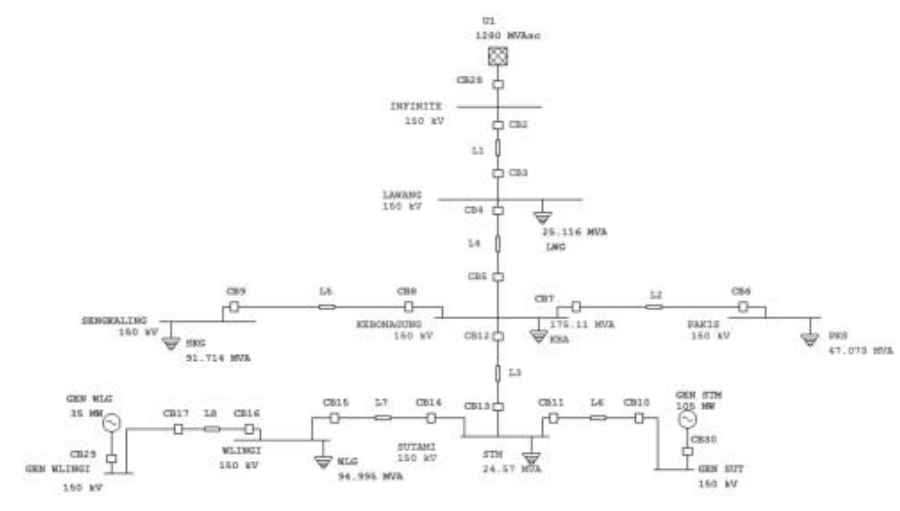

Fig. 1.The Initial Design of the $150 \mathrm{kV}$ Main System in Greater Malang

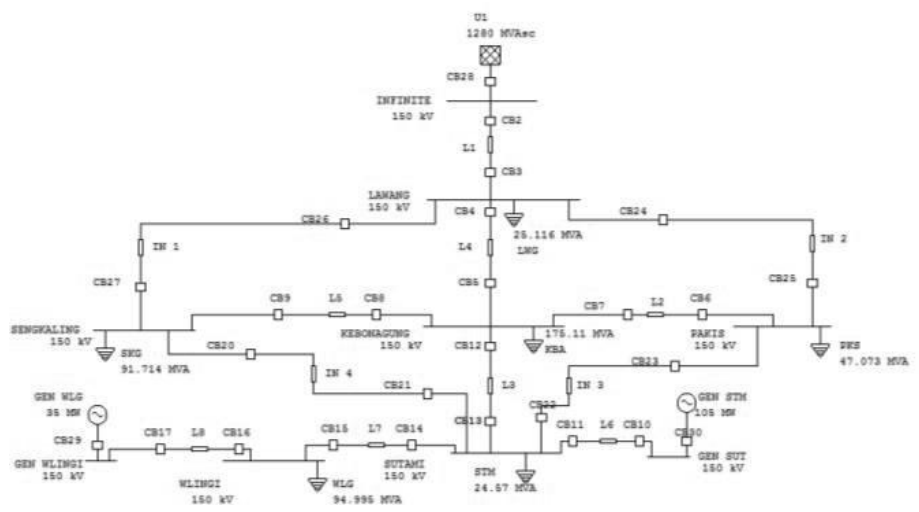

Fig. 2.The Design After Additional $150 \mathrm{kV}$ Transmission Network Interconnection in Greater Malang 


\section{Result}

The additional scenarios were performed through five scenarios. Scenario 1 was a new transmission network in Lawang-Sengkaling Main Substations, Scenario 2 was a new transmission network in Lawang-Pakis Main Substations, Scenario 3 was a new transmission network in Sutami-Sengkaling Main Substations, Scenario 4 was a new transmission network in Sutami-Pakis Main Substations, and Scenario 5 was a combination of the above four scenarios. The purpose of the additional network interconnection was to increase the capacity, reliability, and quality refinement of customer service. Based on Table II, the initial condition stated that the losses were 0.02 MW and -1.012 MVAR, whereas after new interconnection (Scenario 5) the losses changed into 0.009 MW and -1.892 MVAR. The additional transmission network interconnection was simulated using the ETAP 12.6.0 software.

TABLE 1. AMP FLOW (A) AND LOSSES (KW) IN A TRANSMISSION LINE

\begin{tabular}{|c|c|c|c|c|}
\hline \multirow{2}{*}{ Id } & \multicolumn{2}{|c|}{$\begin{array}{c}\text { Before New } \\
\text { Interconnection }\end{array}$} & \multicolumn{2}{c|}{$\begin{array}{c}\text { After New } \\
\text { Interconnection }\end{array}$} \\
\cline { 2 - 5 } & $\begin{array}{c}\text { Amp flow } \\
(\mathrm{A})\end{array}$ & $\begin{array}{c}\text { Losses } \\
(\mathrm{kW})\end{array}$ & $\begin{array}{c}\text { Amp flow } \\
(\mathrm{A})\end{array}$ & $\begin{array}{c}\text { Losses } \\
(\mathrm{kW})\end{array}$ \\
\hline In 1 & 0 & 0 & 8.461 & 0.001 \\
\hline In 2 & 0 & 0 & 37.78 & 0.015 \\
\hline In 3 & 0 & 0 & 310.9 & 2.322 \\
\hline In 4 & 0 & 0 & 390.9 & 2.795 \\
\hline L1 & 202.8 & 2.709 & 97.29 & 0.623 \\
\hline L2 & 181.2 & 0.301 & 95.65 & 0.084 \\
\hline L3 & 1100 & 16.072 & 506.7 & 3.405 \\
\hline L4 & 107.4 & 0.141 & 31.75 & 0.012 \\
\hline L5 & 353 & 1.077 & 45.81 & 0.018 \\
\hline L6 & 1193 & 0.092 & 1297 & 0.109 \\
\hline L7 & 1.126 & 0 & 1.242 & 0 \\
\hline L8 & 366.4 & 0.009 & 366.5 & 0.009 \\
\hline
\end{tabular}

Table I displays the amp flow and losses condition in each line, before and after. Figure 2 shows the initial design, while Figure 3 presents the design after a new interconnection. Table I shows that the losses in L1-L5 transmission line after new interconnection was reduced. This reduction occurred because of the new power distribution scenario. The decrease in the current amount that flows through the line also meant a decrease in losses. Meanwhile, the current that flew in the L7 transmission line experienced an increase after new interconnection because the power distribution was given by the closest source, the PLTA Wlingi. Table II presents the Loading (MW) and Amp loading (A) condition in a bus before and after scenarios. Based on that table, the buses experienced an increase and decreased in both conditions. Similar to the explanation for Table I; these conditions were caused by the scenario.

The data in Table III is the simulation results after the additional new network in Lawang-Sengkaling (Scenario 1), Lawang-Pakis (Scenario 2), Sutami-Sengkaling (Scenario 3), and Sutami-Pakis (Scenario 4). The data explained the effect of additional interconnections to the system when the addition was performed in stages. Additional interconnection in Lawang-Sengkaling (Scenario 1) and Lawang-Pakis (Scenario 2) did not show significant power flow. This occurrence was caused by the new interconnected influenced the closest location, and in this case, was Jamali-Lawang and Lawang-Kebonagung system power grid. New transmission network in Scenario 3 and 4 experienced capacity increase in Sutami and Wlingi generations because the new transmission was located closer. Therefore, to meet the overall load in the generator, there needed a capacity improvement in the power plant.

Based on the analysis, it can be concluded that due to Scenario 5, if there are network maintenance and repairment or disruption, the power distribution could still work continuously by diverting the power distribution to the possible alternative line. In this case, they are Scenario 1, Scenario 2, Scenario 3, and Scenario 4. Thus, the primary system in Greater Malang would no longer be centered in Kebonagung Main Substation and the load growth would not result in overcapacity. 
TABLE II. LOADING (MW) AND AMP LOADING (A) IN BUSBARS BEFORE AND AFTER SCENARIOS

\begin{tabular}{|l|c|c|c|c|}
\hline \multirow{2}{*}{\multicolumn{1}{c|}{ BUS ID }} & \multicolumn{2}{c|}{ Before New Interconnection } & \multicolumn{2}{c|}{ After New Interconnection } \\
\cline { 2 - 5 } & $\begin{array}{c}\text { Loading } \\
\text { (MW) }\end{array}$ & $\begin{array}{c}\text { Amp } \\
\text { Loading } \\
\text { (A) }\end{array}$ & $\begin{array}{c}\text { Loading } \\
\text { (MW) }\end{array}$ & $\begin{array}{c}\text { Amp } \\
\text { loading } \\
\text { (A) }\end{array}$ \\
\hline Sutami Generation & 274.634 & 1193 & 299.843 & 1297 \\
\hline Wlingi Generation & 79.736 & 366.4 & 79.766 & 366.5 \\
\hline JAMALI system power grid & 46.639 & 202.6 & 21.421 & 97.12 \\
\hline Kebonagung & 275.619 & 1207 & 155.24 & 674 \\
\hline Lawang & 46.637 & 202.8 & 31.07 & 133.2 \\
\hline Pakis & 41.167 & 181.2 & 75.023 & 310.9 \\
\hline Sengkaling & 79.225 & 353 & 90.856 & 396.6 \\
\hline Sutami & 274.86 & 1194 & 300.097 & 1298 \\
\hline Wlingi & 79.736 & 366.4 & 79.766 & 366.5 \\
\hline
\end{tabular}

TABLE III. CONDITION RESULTS IN EACH SCENARIO

\begin{tabular}{|c|c|c|c|c|c|c|}
\hline ID & Initial & $\begin{array}{c}\text { Scenario } \\
\mathbf{1}\end{array}$ & $\begin{array}{c}\text { Scenario } \\
\mathbf{2}\end{array}$ & $\begin{array}{c}\text { Scenario } \\
\mathbf{3}\end{array}$ & $\begin{array}{c}\text { Scenario } \\
\mathbf{4}\end{array}$ & $\begin{array}{c}\text { Scenario } \\
\mathbf{5}\end{array}$ \\
\hline Load- MW & 401.01 & 401.01 & 401.01 & 401.02 & 401.02 & 401.03 \\
\hline Load- MVAR & 220.03 & 219.91 & 219.88 & 219.68 & 219.79 & 219.17 \\
\hline $\begin{array}{c}\text { Generation- } \\
\text { MW }\end{array}$ & 401.01 & 401.01 & 401.01 & 401.02 & 401.02 & 401.03 \\
\hline $\begin{array}{c}\text { Generation- } \\
\text { MVAR }\end{array}$ & 220.03 & 219.91 & 219.88 & 219.68 & 219.79 & 219.17 \\
\hline Loss- MW & 0.02 & 0.02 & 0.02 & 0.015 & 0.012 & 0.009 \\
\hline Loss- MVAR & -1.012 & -1.129 & -1.166 & -1.372 & -1.267 & -1.892 \\
\hline
\end{tabular}

\section{Conclusion}

Additional scenarios were needed to increase the power distribution continuity, improve the capacity, reliability, and refinement, and reduce losses in the primary system. There were five scenarios. Scenario 1 was an additional transmission network in Lawang-Sengkaling Main Substations, Scenario 2 was an additional transmission network in Lawang-Pakis Main Substations, Scenario 3 was an additional transmission network in Sutami-Sengkaling Main Substations, Scenario 4 was an additional transmission network in Sutami-Pakis Main Substations, and Scenario 5 was a combination of the above four scenarios. If these scenarios were realized, the $150 \mathrm{kV}$ primary system would not be centered in one main substation but interconnected to all primary substations. Thus, there were higher power distribution continuity and lower losses with a value of 0.009 MW.

\section{References}

[1] H. M. Al-Hamadi and S. A. Soliman, "Long-term/mid-term electric load forecasting based on shortterm correlation and annual growth," Electr. Power Syst. Res., vol. 74, no. 3, pp. 353-361, Jun. 2005 , doi: 10.1016/j.epsr.2004.10.015.

[2] K. B. Lindberg, S. J. Bakker, and I. Sartori, "Modelling electric and heat load profiles of nonresidential buildings for use in long-term aggregate load forecasts," Util. Policy, vol. 58, pp. 63-88, Jun. 2019, doi: 10.1016/j.jup.2019.03.004.

[3] E. Hirst, "Conservation programs can cut load-growth uncertainty for electric utilities," Technol. Forecast. Soc. Change, vol. 36, no. 4, pp. 415-424, Dec. 1989, doi: 10.1016/0040-1625(89)90032-2.

[4] D. A. G. Vieira, B. E. Silva, T. V. Menezes, and A. C. Lisboa, "Large scale spatial electric load forecasting framework based on spatial convolution," Int. J. Electr. Power Energy Syst., vol. 117, p. 105582, May 2020, doi: 10.1016/j.ijepes.2019.105582.

[5] Q. J. Kwong, J. E. Lim, and M. S. Hasim, "Miscellaneous electric loads in Malaysian buildings Energy management opportunities and regulatory requirements," Energy Strategy Rev., vol. 21, pp. 35-49, Aug. 2018, doi: 10.1016/j.esr.2018.04.002. 
[6] S. Moreno-Carbonell, E. F. Sánchez-Úbeda, and A. Muñoz, "Rethinking weather station selection for electric load forecasting using genetic algorithms," Int. J. Forecast., p. S0169207019302328, Dec. 2019, doi: 10.1016/j.ijforecast.2019.08.008.

[7] F. S. Abu-Mouti and M. E. El-Hawary, "Optimal Distributed Generation Allocation and Sizing in Distribution Systems via Artificial Bee Colony Algorithm," IEEE Trans. Power Deliv., vol. 26, no. 4, pp. 2090-2101, Oct. 2011, doi: 10.1109/TPWRD.2011.2158246.

[8] P. Cuffe and A. Keane, "Visualizing the Electrical Structure of Power Systems," IEEE Syst. J., vol. 11, no. 3, pp. 1810-1821, Sep. 2017, doi: 10.1109/JSYST.2015.2427994.

[9] M. C. Carnero and A. Gómez, "Maintenance strategy selection in electric power distribution systems," Energy, vol. 129, pp. 255-272, Jun. 2017, doi: 10.1016/j.energy.2017.04.100.

[10] K. Chandram, N. Subrahmanyam, and M. Sydulu, "Equal embedded algorithm for economic load dispatch problem with transmission losses," Int. J. Electr. Power Energy Syst., vol. 33, no. 3, pp. 500507, Mar. 2011, doi: 10.1016/j.ijepes.2010.12.002.

[11] A. Grange, A. Marrel, J. B. Droin, F. Bertrand, O. Boutin, and J. H. Ferrasse, "Loss of off-site power transient analysis for a sodium-cooled fast reactor equipped with a gas power conversion system and preliminary optimisation of its operation," Nucl. Eng. Des., vol. 355, p. 110315, Dec. 2019, doi: 10.1016/j.nucengdes.2019.110315.

[12] A. Mohamed Imran and M. Kowsalya, "A new power system reconfiguration scheme for power loss minimization and voltage profile enhancement using Fireworks Algorithm," Int. J. Electr. Power Energy Syst., vol. 62, pp. 312-322, Nov. 2014, doi: 10.1016/j.ijepes.2014.04.034.

[13] W. Bai, I. Eke, and K. Y. Lee, "An improved artificial bee colony optimization algorithm based on orthogonal learning for optimal power flow problem," Control Eng. Pract., vol. 61, pp. 163-172, Apr. 2017, doi: 10.1016/j.conengprac.2017.02.010.

[14] M. A. Elizondo, F. K. Tuffner, and K. P. Schneider, "Three-Phase Unbalanced Transient Dynamics and Powerflow for Modeling Distribution Systems With Synchronous Machines," IEEE Trans. Power Syst., vol. 31, no. 1, pp. 105-115, Jan. 2016, doi: 10.1109/TPWRS.2015.2389712.

[15] Z. Ren, K. Wang, W. Li, L. Jin, and Y. Dai, "Probabilistic Power Flow Analysis of Power Systems Incorporating Tidal Current Generation," IEEE Trans. Sustain. Energy, vol. 8, no. 3, pp. 1195-1203, Jul. 2017, doi: 10.1109/TSTE.2017.2669139. 